\title{
No-shows at public secondary dental care for pediatric patients: a cross-sectional study in a large Brazilian city
}

\author{
Não comparecimento na atenção secundária pública em saúde \\ bucal de pacientes pediátricos: estudo transversal em uma grande \\ cidade brasileira
}

\author{
Mario Augusto Gori Gomes (https://orcid.org/0000-0002-4816-4712) ${ }^{1}$ \\ Mauro Henrique Nogueira Guimarães Abreu (https://orcid.org/0000-0001-8794-5725) ${ }^{2}$ \\ Fernanda Morais Ferreira (https://orcid.org/0000-0001-9400-1167) ${ }^{2}$ \\ Fabian Calixto Fraiz (https://orcid.org/0000-0001-5290-7905) ${ }^{3}$ \\ José Vitor Nogara Borges Menezes (https://orcid.org/0000-0001-9178-0898) ${ }^{3}$
}

${ }^{1}$ Universidade Federal do Paraná. R. XV de Novembro 1299, Centro. 80060000 Curitiba PR Brasil. marioaugustogomes@ gmail.com

${ }^{2}$ Faculdade de Odontologia, Universidade Federal de Minas Gerais. Belo Horizonte MG Brasil. ${ }^{3}$ Departamento de Estomatologia, Setor de Ciências da Saúde, Universidade Federal do Paraná. Curitiba PR Brasil.
Abstract Missed appointments have a great economic, social and administrative impact on the management of public health services. This research aimed to study factors associated with non-attendance to the first appointments of pediatric patients in secondary dental care services in the city of Curitiba, Brazil. A cross-sectional study was performed using secondary data from the electronic health records of the Curitiba $\mathrm{Mu}$ nicipal Secretary of Health. The study included all children (0-12 years) referred to secondary dental clinics in the years 2010 to 2013. Data were analyzed by the chi-square test and Pearson linear trend chi-square $(\alpha=0.05)$. Binary logistic regression models were built. Data from 1,663 children were assessed and the prevalence of non-attendance was $28.3 \%$. The variables associated with the non-attendance in inferential analysis ( $p$ $<0.05$ ) and in the final model were the household income per capita (95\% CI: 1.93-2.82) and the waiting time in virtual queue (95\% CI: $1.000-$ 1.002). Socioeconomic aspects and the waiting time in virtual queue, should be considered in the strategic planning of health services as they may influence the attendance of pediatric patients in secondary dental referral service.

Key words Dental care, Secondary care, Pediatric dentistry
Resumo O não comparecimento a consultas tem um grande impacto no gerenciamento dos serviços de saúde pública. O objetivo foi avaliar os fatores associados ao não comparecimento às primeiras consultas de pacientes pediátricos nos serviços de atenção secundária em saúde bucal na cidade de Curitiba, Brasil. Um estudo transversal foi desenvolvido com dados secundários obtidos de cadastros eletrônicos da Secretaria Municipal de Saúde de Curitiba. Participaram crianças de 0 a 12 anos de idade encaminhadas para atenção secundária nos anos de 2010 a 2013. Os dados foram analisados pelos testes de qui-quadrado de Pearson e qui-quadrado de tendência linear $(\alpha=0,05)$. Foram constituídos modelos de regressão logística binária. Foram analisados os dados de 1.663 crianças. A prevalência de não comparecimento às primeiras consultas foi de $28,3 \%$. As variáveis que estiveram associadas ao não comparecimento na análise inferencial $(p<0,05)$ e no modelo final foram a renda per capita familiar (95\% CI: 1,932,82) e o tempo de espera em fila virtual (95\% CI: 1,000-1,002). Aspectos econômicos e o tempo de espera em fila virtual devem ser considerados no planejamento estratégico dos serviços públicos de saúde bucal, pois podem influenciar o comparecimento de pacientes na atenção secundária.

Palavras-chave Assistência odontológica, Atenção secundária à saúde, Odontopediatria 


\section{Introduction}

In Brazil, public dental care is organized through the Brazilian Unified National Health System $(\mathrm{SUS})^{1}$. This system provides universal access to health services at all levels of health assistance. The integrality of the services provided is a fundamental principle of the system, and it is based on the concept that all levels of health treatment must be available, so that an individual can achieve effective wellbeing. Despite some political, administrative and social difficulties, the system offers basic care that focuses on primary health promotion and disease prevention, and secondary care, when necessary, using a system of referrals to dental specialty centers $(\mathrm{CEO})^{2}$. Although the scheduling of such appointments is apparently a simple process, many problems need to be overcome before the system can work with the expected regularity and efficiency ${ }^{3}$.

Failure to appear for scheduled appointments with no prior notification of cancellation in secondary healthcare has proven to be a major challenge for public administrators because it negatively influences indicators of the quality of services that are offered to the population in all realms of healthcare ${ }^{4-6}$. The first appointment in secondary dental care is mainly a time during which the patient ensures the continuation of treatment within the public oral healthcare network. Failure to appear for further appointments leads to a lack of continuity of the planned treatment, which negatively impacts the individual's oral health and leads to a waste of both human and material resources that are allocated to such appointments ${ }^{7}$.

In adults, the literature already reports various factors that are associated with the failure to appear for scheduled medical and dental appointments, such as communication problems between the health institution and the public ${ }^{8}$, a lack of confidence in the public healthcare system $^{9}$, the impossibility of missing a day of work $^{10,11}$, forgetfulness ${ }^{12}$, fear and anxiety associated with the possibility of experiencing pain ${ }^{13}$, the distance between the patient's place of residence and the healthcare unit ${ }^{14}$, unavailable public transportation, a lack of understanding the scheduling system ${ }^{15,16}$ and the length of time between the day of scheduling and the appointment ${ }^{17-21}$. However, the identification of the main reasons for the failure of children to appear for prescheduled appointments at secondary dental care centers have not been studied yet.
The knowledge of the factors that are associated with the failure to appear for pediatric dental appointments will offer information to assist administrators in the development of strategies and actions that seek to minimize their negative impact, thereby making the system more effective, ensuring the continuity of care, and improving relationships between patients and public health service providers.

Thus, the aim of the present study was to identify the socioeconomic and demographic factors, as well as dental service usage pattern and service features that are associated with the failure of pediatric dental patients to appear at their first prescheduled appointment at secondary healthcare units in the city of Curitiba, Paraná, Brazil.

\section{Material and methods}

An analytical, cross-sectional study that used quantitative methodology was conducted in the city of Curitiba using secondary data that were obtained from the Appointment Scheduling Center (CMC), which is managed by the Municipal Secretary of Health (SMS).

\section{Characterization of population and field study}

The city of Curitiba is the capital of the state of Paraná, in southern Brazil. According to data from the 2010 census, Curitiba has a population of $1,751,907$ people $^{22}$. The public healthcare system is managed by the SMS, comprising 108 primary healthcare units with dental services that are distributed throughout the nine administrative districts of the city. There are two Dental Specialties Centers (CEO) for patients who require specialized care in root canal treatment, minor oral surgery, periapical radiology, periodontics, stomatology, and dental prostheses, individuals with special needs, and the pediatric population. Each center has two pediatric dentists.

Patients gain access to CEOs through an initial dental appointment in a primary healthcare unit, where dentists refer patients who require secondary care to CEOs according to protocols that were established by the SMS. Scheduling for specialties is performed through the CMC, which places patients on a waiting list for the specialty that is requested by the referring dentist. The CMC follows the chronological order of inclusion on the waiting list and authorizes appointments based on availability. If an appointment is 
available at the time of scheduling, then the patient leaves the primary healthcare unit with the time and date of the appointment already scheduled. If the patient is placed on a waiting list, then the primary healthcare unit informs the patient when an appointment becomes available later.

When an appointment to secondary dental care is rescheduled or cancelled, there is a need to contact the next child's family registered in the virtual queue to attend the appointment. Human resources, usually community health agents, from the primary healthcare units are mobilized to go to the family residences to confirm whether they will attend the secondary dental care appointment available or not. The deadline for this operation, defined by the SMS, is 48 hours. Due to the characteristics of the services provided by the primary healthcare units and the availability of human resources, not always the confirmation is feasible in 48 hours.

The two CEOs in Curitiba are references for secondary oral healthcare in the city. The pediatric dentistry specialty has high percentages of missed appointments $(43.8 \%$ and $50.2 \%$ in 2012 and 2013, respectively), considering all scheduled initial and subsequent appointments ${ }^{23}$. The mean time on the waiting list at the time of data collection was nearly 4 months and 28 days $^{24}$.

\section{Data collection}

Secondary data were obtained from CMC reports that were provided by the Information Technology Office that is linked to the SMS, referring to pediatric dental appointments that were scheduled at dental specialty centers. Data was subsequently analyzed for inconsistencies and incomplete data. Missing data were sought in demographic records and patient charts or through reports from the children's mothers.

The data included the first scheduled appointments of children aged 0-12 years who were referred from primary care units to secondary pediatric dental care services at the two CEOs in Curitiba between 2010 and 2013. Return appointments and cases in which a patient was referred more than once were excluded, such that each patient was only included once in the sample. The automated system of the SMS registers the results of each appointment as following: show, rescheduled, cancelled, or no-show. For statistical purposes, thisvariable was dichotomized as "showed at the first appointment" or "no-show at the first appointment." The latter included cases of rescheduling, cancellation, and no-show ${ }^{25}$.
Sociodemographic data were collected from the patients' charts, registry files, and mothers' reports. The dependent variable was "no-show" for the first appointment in secondary pediatric dental care. The independent variables were the child's age and sex, time on the waiting list, year of appointment, mother's schooling and marital status, type of residence, household income per capita in administrative district of the city where the primary healthcare of referral was located, type of original healthcare unit, participation in programs at the healthcare unit and missed primary care appointments.

\section{Statistical methods}

The compilation, organization, and codification of the data were performed using Microsoft Excel $^{\mathrm{TM}}$ (Microsoft Corp., Seattle, USA). The statistical analysis was performed using IBM SPSS version 20.0 (IBM Corp, Armonk, USA). The data were categorized as the following: child's sex (male/female), mother's schooling $(\leq 8$ years/> 8 years of formal education), mother's marital status (with/without a partner), type of housing (brick and mortar/other), household income per capita in administrative district of the city where the primary healthcare of referral was located,( $\leq 2$ state minimum wage/ $>2$ state minimum wage), type of original healthcare unit (conventional basic unit/unit with Family Health Strategies [FHS]), participation in programs at primary healthcare unit (yes/no), missed primary care appointments (yes/no), and year of the scheduled appointment (2010/2011/2012/2013).

Time on the waiting list was determined as the difference between the date of scheduling and date of appointment, and was considered a continuous variable (expressed in days). The child's age was a continuous variable (expressed in years).

A multiple regression model was created with crude and adjusted odds ratio (OR) estimates for "failure to appear" according to the categories of the independent variables. Covariables with a $p$ value $<0.25$ in the univariate logistic regression analysis were incorporated into the multiple model, and Wald's backward method was used for the selection of variables for the model. Only covariables with a $p$ value $<0.05$ remained in the final model. The Hosmer and Lemeshow test was used to determine the goodness of fit of the final model. The linear-trend ${ }^{2}$ test was used to investigate the association between time on the waiting list ( $\leq 1$ month, 1-3 months, $>3$ months) and 
year of appointment. The level of significance was set at $5 \%(p<0.05)$.

\section{Ethical aspects}

This study was approved by the Ethics Committees of the Federal University of Paraná (Brazil) and Curitiba SMS. Because only secondary data were analyzed and no direct risk to or embarrassment of the participants existed, no statement of informed consent was required.

\section{Results}

All the 2307 scheduled appointments for secondary care in pediatric dentistry between January 1 , 2010, and December 31, 2013, were analyzed. 644 return appointments and cases in which a patient was referred more than once were excluded. A total of 1663 scheduled first appointments were analyzed (Figure 1).

The frequency of failure to appear for the first appointment was $28.3 \%$. The mean time on the waiting list was $3.2 \pm 0.1$ months (median $=2.6$ months) for patients who appeared for appointments in secondary pediatric dental care and 3.9 \pm 0.1 months (median $=4.2$ months) for those who failed to appear for their appointments. This difference was statistically significant in the univariate logistic regression model $(p<0.001)$.

Failure to appear for appointments was associated with the household income per capita in administrative district of the city where the primary healthcare of referral was located and time on the waiting list, independent of the other variables. Patients referred from primary health care units in the southern region had a 2.33-fold (95\% confidence interval [CI]: 1.93-2.82) greater chance of failing to appear than those from the northern region of the city. Each additional day on the waiting list increased the chance of failing to appear by $0.1 \%$ (Table 1 ).

\section{Discussion}

In the present study, the failure of children to appear for their first dental appointment in secondary care was frequent and associated with a longer time on the waiting list. Although no previous studies were found on this issue involving the pediatric population, Brazilian studies with adults have reported the influence of wait times on the failure to appear at dental reference ser- vices $^{10,17,26}$. Similar findings are described for other fields of health in different countries ${ }^{6,18,20,21,27-29}$.

Each additional day on the waiting list lead to a $0.1 \%$ greater chance of failing to appear, or $3 \%$ every 30 days. The current waiting time for an appointment at secondary dental care in the city of Curitiba at the time data were collected, was more than 4 months ${ }^{23}$. Pediatric dental patients who are referred for secondary care have an approximately $36.4 \%$ chance of failing to appear for their appointments. A study in the field of general health demonstrated that the maximum wait time that would lead to a $60 \%$ reduction of missed appointments would be 2 weeks ${ }^{21}$. Apparently, cases of failure to appear will continue to grow if there is no wait time follow-up system or other form of scheduling that reduces the amount of time between the appointment requests and availability of appointments.

Different hypotheses have been proposed to explain this association. The treatment that motivated the referral may no longer be necessary by the time the appointment is scheduled. The caregiver may have taken the child to a private practice to obtain more timely treatment. The child may have been sent to an urgent care unit that solved the problem (often through tooth extraction). With the aim of preserving the patient's health and following clinical protocols, the referring dentist may have encouraged the child's caregiver to accept the referral when the caregiver in fact expected a faster solution of the problem or did not intend to show up for secondary care.

The percentage of patients who wait for appointments for longer periods of time has increased over the years. Such factors as an increase in demand and a reduction of the offer of pediatric dental appointments may have contributed to this situation.

The prevalence of missed appointments was $28.3 \%$, which is lower than reports in previous studies from the same institution, in which the prevalence rates for 2012 and 2013 were 43.8 and $50.2 \%$, respectively ${ }^{23}$. However, return appointments and further referrals of the same patient were considered in these reports, whereas only the failure to appear for the first appointment was considered in the present investigation. Different data collection methods and types of services that are surveyed hinder comparisons with previous findings in the literature. Studies that involved adult patients ${ }^{30,31}$ and adolescents ${ }^{12}$ reported prevalence rates of missed appointments that ranged from $9.9 \%$ to $58.3 \%$. Some studies focused on searching for solutions to financial losses in pri- 


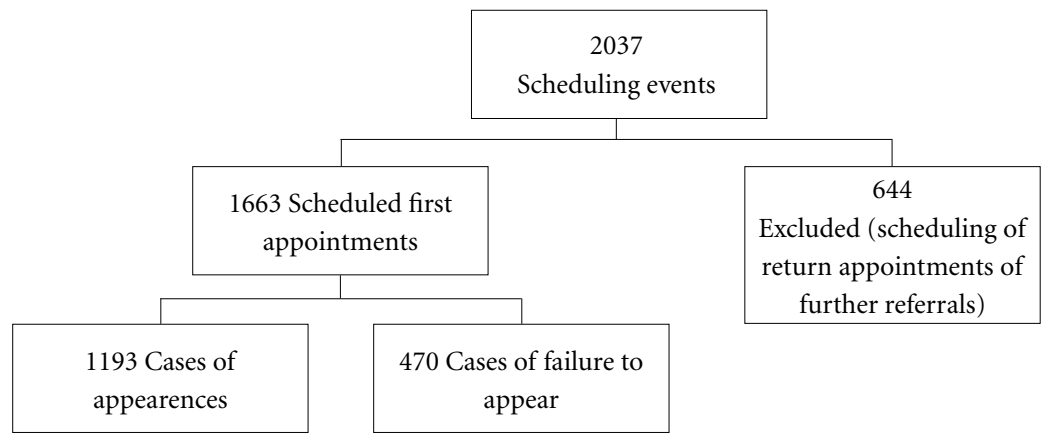

Figure 1. Flowchart of the sample.

vate practice ${ }^{25,32}$ whereas others focused on the efficient use of human, material, and financial resources in public services ${ }^{4,33}$. The different methodologies of the studies and the fact that the present investigation was one of the first to involve the specialty of pediatric dentistry make comparisons of prevalence rates more difficult.

Studies of adults in public dental services in Brazil have reported rates of failure to appear that ranged from $32.9 \%$ to $43 \%{ }^{10,17,26}$. The divergent rates from the present study may be related to the specificity of the pediatric dentistry specialty, which was not investigated in these previous studies. A possible explanation may be that parents apply themselves more when the treatment of their children is at stake compared with tending to their own health. An adult may be willing to cancel other commitments to ensure that the child attends an appointment. Children who are referred to pediatric dentistry in secondary care have presented problems related to behavior and cooperation in primary care $e^{9,34,35}$. Parents may see an appointment with a specialist as a more effective treatment option. Moreover, the characteristics of different populations may have influenced the different prevalence rates that have been reported.

The only previous study on missed appointments in the specialty of pediatric dentistry in Brazil was conducted with the aim of investigating differences between referrals from primary care health units with and without Family Health Strategies $^{36}$. The authors found rates of failure to appear of $7.14 \%$ and $16.67 \%$ for patients who were referred by conventional health units and units with Family Health Strategies, respectively, but this difference did not achieve statistical significance, which is consistent with the results of the present study. The different prevalence rates of missed appointments may be explained by the fact that the previous study was conducted in a small city in terms of both population and area, with fewer health units and different administrative aspects. In the present study, sociodemographic factors, such as the child's age and sex, mother's schooling and marital status, type of residence, and participation of the family in health units in the community, were not associated with missed appointments, which contrasts with data that are described in the literature. A systematic review that was performed to identify the main factors associated with the attitudes of parents who provide regular dental care for their children concluded that socioeconomic status, the level of education, and behavioral aspects play fundamentally important roles ${ }^{37}$. In adults, age and sex have been associated with missed appointments in secondary care ${ }^{17}$. However, the structures and geographic distribution of health services, public transportation, and urban planning in the city of Curitiba may have minimized the weight of these variables in the present study.

A significant difference was found between the family income from the administrative districts of the city where the primary healthcare of referral was located. Patients from the districts of the city, which have a lower family income $(\leq 2 \mathrm{MW})^{38}$, had a 2.33 -fold (95\% CI: $\left.1.93-2.82\right)$ greater chance of failing to appear for the first appointment. This finding agrees with previous 
Table 1. Factors associated with missed pediatric dental appointments in secondary care, Curitiba, Brazil, 20102013.

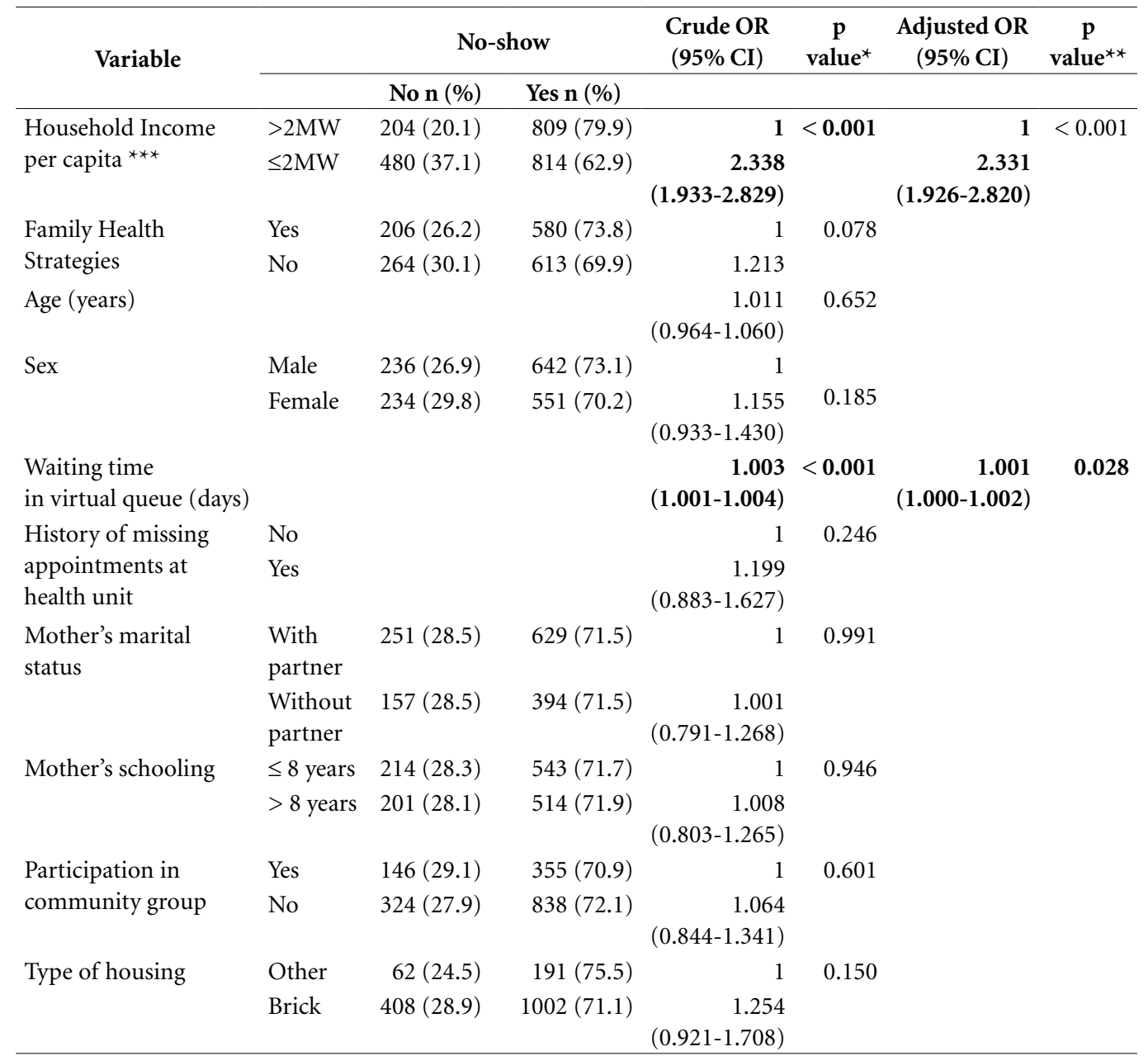

${ }^{\star}$ Univariate logistic regression; ${ }^{* *}$ multiple logistic regression; Hosmer and Lemeshow test for goodness of fit of model, $p=0.558$. ${ }_{\star * *}$ Household income per capita in the administrative district of the city where the primary healthcare of referral was located. Significant results are shown in bold.

studies, in which an association was found between missed appointments and the level of social vulnerability of the patients ${ }^{26,39,40}$.

Failure to appear for dental appointments leads to a waste of financial and human resources, infrastructure and time, and delayed treatment for both the patients who fail to appear and others who could have filled the appointment time $\operatorname{slot}^{16}$. Solutions with the aim of minimizing the frequency of missed appointments have been the object of many studies. Appointment confirmations by the local health team, whether in person or by telephone, letter, email, or text message, have been widely used and have achieved good results $^{25,27,29,30,41-43}$. Certain aspects are fundamental to reduce the rate of missed appointments, such as strengthening the training of health teams at the local level to achieve more rigor in referrals, provide greater integration between primary and secondary levels of care, encourage community involvement, and maintain the focus on the population $^{44}$. Moreover, determinations should be made regarding whether the patient desires and is able to visit a secondary care service ${ }^{10}$.

Broadening the range of services that are offered in primary care could help reduce the number of referrals. Patients benefit when specialized procedures have a low degree of complexity and can be performed at the primary care level because patients can undergo most, if not all, treatments when the health unit is closer to home ${ }^{45}$. Such procedures in pediatric dentistry include space maintainers, labial frenectomy, and pulp therapy, among others. 
The failure to appear for appointments will likely never disappear completely, but addressing its main predictor (i.e., wait times) could significantly reduce the rates of missed appointments ${ }^{46}$. There is likely no single solution or intervention, but primary healthcare units should nonetheless propose solutions that are adapted to the local characteristics of the population to ensure greater access to services ${ }^{47}$.

Considering the limitations of the study, especially those related to secondary data analysis, this is the first study that aims a better understanding of the associated factors to non-attendance to public secondary dental care for pediatric patients. The results highlight that the waiting time in the virtual queue and socioeconomic aspects related to the primary healthcare unit of referral are associated to non-attendance. This information will be useful especially for the Brazilian public healthcare system managers, to define strategic planning of dental health services aiming regularity and efficiency. These conclusions must be considered when planning further studies on the area.

Although the present results clearly demonstrate that wait times are a fundamental factor in the failure to appear for appointments in secondary care, we were unable to determine possible associations with other factors, such as household income, distance from the patients' home to the dental specialty centers, or whether socioeconomic aspects influence cases of missed appointments. The reason for the inability to establish such associations was the unavailable and inconsistent information in databases of the SMS, which can be considered a limitation of studies that involve secondary data. Studies with the aim of obtaining greater details on issues that involve the distance from the patients' primary health units to CEOs and the socioeconomic aspects of the families, could provide additional insights into possible association s. Issues related to the workflow of oral health teams at the local level should also be investigated. Moreover, routines that can control wait times, confirmations of specialized appointments, and rigor in the selection and diagnosis of the clinical needs of patients who are referred to specialists should be analyzed.

Any solutions that are implemented should be subjected to periodic evaluations from the standpoint of both the health team and patients. Oftentimes, eliminating the waiting list simply masks demand. Likewise, limiting scheduling could give the false impression that the demand is lower than it is. Public health services in a large city cannot have homogeneous conduct in which each health team interprets the directives in its own way or creates scheduling routines that favor the health unit more than the patients.

The institution is responsible for establishing the best relationship between demand and the number of appointments that are offered while making the best use of physical and budgetary resources. The teams at health units and dental specialty centers should create environments and workflows that strengthen the link with patients and facilitate access to secondary care. 


\section{Collaborations}

MAG Gomes, FC Fraiz and JVNB Menezes substantial contributions to the conception or design of the study, acquisition, and interpretation of data. Final approval of the version to be published. Agreement to be accountable for all aspects of the work in ensuring that questions related to the accuracy or integrity of any part of the work are appropriately investigated and resolved. Drafting the work or revising it critically for important intellectual content. MHNG Abreu and FM Ferreira - substantial contributions to the conception and design of the study, analysis and interpretation of data. Final approval of the version to be published. Agreement to be accountable for all aspects of the work in ensuring that questions related to the accuracy or integrity of any part of the work are appropriately investigated and resolved. Drafting the work or revising it critically for important intellectual content.

\section{References}

1. Brasil. Decreto Federal $n^{\circ} 7.508$, de 28 de junho de 2011. Regulamenta a Lei 8.080, de 19 de setembro de 1990, para dispor sobre a organização do Sistema Único de Saúde-SUS, o planejamento da saúde, a assistência à saúde e a articulação interfederativa, e dá outras providências. Diário Oficial da União 2011; 29 jun.

2. Góes PSA, Figueiredo N, Neves JC, Silveira FMM, Costa JFR, Pucca Jr GA, Rosales MS. Avaliação da atenção secundária em saúde bucal: uma investigação nos centros de especializade do Brasil. Cad Saude Publica 2012; 28(Supl.):s81-s89.

3. Chaves SCL, Soares FF, Rossi TRA, Cangussu MCT, Figueiredo ACL, Cruz DN, Cury PR. Características do acesso e utilização dos serviços odontológicos em municípios de médio porte. Cien Saude Colet 2012;17(11):3115-3124.

4. Schmalzried HD, Liszak J. A model program to reduce patient failure to keep scheduled medical appointments. J Community Health 2012; 37(3):715-718.

5. Hixon AL, Chapman RW, Nuovo J. Failure to keep clinic appointments: implications for residency education and productivity. Fam Med 1999; 31(9):627-630.

6. Lee VJ, Earnest A, Chen MI, Krishnan B. Predictors of failed attendances in a multispecialty outpatient centre using electronic databases. BMC Health Serv Res 2005; 5:51.

7. Whear R, Abdul-Rahman AK, Boddy K, Thompson-Coon J, Perry M, Stein K. The clinical effectiveness of patient initiated clinics for patients with chronic or recurrent conditions managed in secondary care: a systematic review. PLoS One 2013; 8(10):1-11.

8. Hertz P, Stamps PL. Appointment-keeping behavior re-evaluated. Am J Public Health 1977; 67(11):10331036.

9. Hallberg U, Camling E, Zickert I, Robertson A, Berggren U. Dental appointment no-shows: Why do some parents fail to take their children to the dentist? Int $J$ Paediatr Dent 2008;18(1):27-34.

10. Zaitter WM, Silva M, Biazevic MGH, Crosato E, Pizzato E, Michel-Crosato E. Avaliação da acessibilidade do paciente à clínica de especialidades em Endodontia em dois distritos de saúde do município de Curitiba (PR). Rev Sul-bras Odontol 2009; 6(4):413-421.

11. Gonçalves CA, Vazquez FL, Ambrosano GMB, Mialhe FL, Pereira AC, Sarracini KLM, Guerra LM, Cortellazzi KL. Estratégias para o enfrentamento do absenteísmo em consultas odontológicas nas Unidades de Saúde da Família de um município de grande porte: uma pesquisa-ação. Cien Saude Colet 2015; 20(2):449-460.

12. Skaret E, Raadal M, Kvale G, Berg E. Factors related to missed and cancelled dental appointments among adolescents in Norway. Eur J Oral Sci 2000; 108(3):175-183.

13. Sohn W, Ismail A, Amaya A, Lepkowski J. Determinants of dental care visits among low-income African-American children. J Am Dent Assoc 2007; 138(3):309-318.

14. Curtis B, Evans RW, Sbaraini A, Schwarz E. Geographic location and indirect costs as a barrier to dental treatment: a patient perspective. Aust Dent J 2007; 52(4):271-275.

15. Lacy NL, Paulman A, Reuter MD, Lovejoy B. Why we don't come: patient perceptions on no-shoes. Ann Fam Med 2004; 2(6):541-545. 
16. George A, Rubin G. Non-attendance in general practice: a systematic review and its implications for access to primary health care. Fam Pract 2003; 20(2):178-184.

17. Machado AT, Werneck MAF, Lucas SD, Abreu MHNG. Who did not appear? First dental visit absences in secondary care in a major Brazilian city: a cross-sectional study. Cien Saude Colet 2015; 20(1):289-298.

18. Cronin PR, DeCoste L, Kimball AB. A multivariate analysis of dermatology missed appointment predictors. JAMA Dermatol 2013; 149(12):1435-1437.

19. Rose K, Ross J, Horwitz L. Advanced access scheduling outcomes: a systematic review. Arch Intern Med 2011; 171(13):1150-1159.

20. Harrington DW, Wilson K, Rosenberg M, Bell S. Access granted! Barriers endure: determinants of difficulties accessing specialist care when required in Ontario, Canada. BMC Health Serv Res 2013; 13:146.

21. McMullen MJ, Netland PA. Lead time for appointment and the no-show rate in an ophthalmologic clinic. Clin Ophthalmol 2015; 9:513-516.

22. Instituto Brasileiro de Geografia e Estatística (IBGE). Censo 2010. [cited 2014 Sep 15]. Available from: http:// censo2010.ibge.gov.br.

23. Curitiba. Secretaria Municipal de Saúde (SMS). Relatório do Sistema e-Saúde. Curitiba: SMS; 2013.

24. Curitiba. Secretaria Municipal de Saúde (SMS). Relatório da Central de Marcação de Consultas. Curitiba: SMS; 2013.

25. Christensen AA, Lugo RA, Yamashiro DK. The effect of confirmation calls on appointment-keeping behavior of patients in a children's hospital dental clinic. Pediatr Dent 2001; 23(6):495-498.

26. Bender AS, Molina LR, Mello ALSF. Absenteísmo na atenção secundária e suas implicações na atenção básica. RevSaude Publica Paraná 2010; 11(2):56-65.

27. Ross LV, Friman PC, Christophersen ER. An appointment-keeping improvement package for outpatient pediatrics: systematic replication and component analysis. J Appl Behav Anal 1993; 26(4):461-467.

28. Norris JB, Kumar C, Chand S, Moskowitz H, Shade SA, Willis DR. An empirical investigation into factors affecting patient cancellations and no-shows at outpatient clinics. Decis Support Syst 2014; 57(1):428-443.

29. Parikh A, Gupta K, Wilson AC, Fields K, Cosgrove NM, Kostis JB. The effectiveness of outpatient appointment reminder systems in reducing no-shows rates. Am J Med 2010; 123(6):542-548.

30. Horvath M, Levy J, Engle P, Carlson B, Ahmad A, Ferranti J. Impact of health portal enrollment with email reminders on adherence to clinic appointments: a pilot study. J Med Internet Res 2011; 13(2):e41.

31. Listl S, Moeller J, Manski R. A multi-country comparison of reasons for dental non-attendance. Eur J Oral Sci 2014; 122(1):62-69.

32. Berg BP, Murr M, Chermak D, Woodall J, Pignone M, Sandler RS, Denton BT. Estimating the cost of noshows and evaluating the effects of mitigation strategies. Med Decis Making 2013; 33(8):976-985.

33. Oleskovicz M, Oliva FL, Grisi CCH, Lima AC, Custódio I. Overbooking in an outpatient healthcare facility in the Brazilian Unified National Health System. Cad Saude Publica 2014; 30(5):1009-1017.
34. Wigen TI, Skaret E, Wang NJ. Dental avoidance behavior in parent and child as risk indicators for caries in 5-year old children. Int J Paediatr Dent 2009; 19(6):431-437.

35. Wang NJ, Aspelund GO. Children who break dental appointments. Eur Arch Paediatr Dent 2009; 10(1):11-14.

36. Bulgareli JV, Faria ET, Ambrosano GMB, Vazquez FL, Cortelazzi KL, Meneguim MC, Mialhe FL, Pereira AC. Informações da atenção secundária em Odontologia para avaliação dos modelos de atenção à saúde. Rev Odontol UNESP 2013; 42(4):229-236.

37. Badri P, Saltaji H, Flores-Mir C, Amin M. Factors affecting children's adherence to regular dental attendance: a systematic review. J Am Dent Assoc 2014; 145(8):817-828.

38. United Nations Development Programme (UNDP). Atlas do desenvolvimento humano no Brasil 2013. Perfil Municipal de Curitiba, PR. [cited 2014 Apr 12]. Available from: http://atlasbrasil.org.br/2013/pt/perfil/curitiba_pr

39. Samuels RC, Ward VL, Melvin P, Macht-Greenberg M, Wenren LM, Yi J, Massey G, Cox JE. Missed appointments: Factors contributing to high no-show rates in an urban pediatrics primary care clinic. Clin Pediatr (Phila) 2015; 54(10):976-982.

40. Kaplan-Lewis E, Percac-Lima S. No-show to primary care appointments: why patients do not come. J Prim Care Community Health 2013; 4(4):251-255.

41. Perron NJ, Dao MD, Kossovski MP, Miserez V, Chuard C, Calmy A, Gaspoz JM. Reduction of missed appointments at an urban primary care clinic: a randomized controlled study. BMC Fam Pract 2010; 11:79.

42. Molfenter T. Reducing appointment no-shows: going from theory to practice. Subst Use Misuse 2013; 48(9):743-749.

43. Almog DM, Devries JA, Borreli JA, Kopycka-Kedzierawski DT. The reduction of broken appointment rates through an automated appointment confirmation system. J Dent Educ 2003; 67(9):1016-1022.

44. Nicholson C, Jackson C, Marley J. A governance model for integrated primary/secondary care for the health-reforming first world - results of a systematic review. BMC Health Serv Res 2013; 13:528.

45. Chaves SCL, Cruz DN, Barros SG, Figueiredo AL. Avaliação da oferta e utilização de especialidades odontológicas em serviços públicos de atenção secundária na Bahia, Brasil. Cad Saude Publica 2011; 27(1):143-154.

46. Sharp DJ, Hamilton W. Non-attendance at general practices and outpatient clinics. BMJ 2001; 323(7321):1081-1082.

47. Lehmann TNO, Aebi A, Lehmann D, Balandraux-Olivet $\mathrm{M}$, Stalder $\mathrm{H}$. Missed appointments at a swiss university outpatient clinic. Public Health 2007; 121(10):790799.

Artigo apresentado em 12/04/2017

Aprovado em 01/09/2017

Versão final apresentada em 03/09/2017 
